\title{
Vulnerabilidade social, abordagem territorial e proteção na política de assistência social
}

\author{
Social vulnerability, territorial approach and the protection of social assistance policy
}

\author{
Priscila Semzezem* \\ Jolinda de Moraes Alves**
}

\begin{abstract}
Resumo:
Este artigo apresenta um estudo que teve como objetivo aprofundar o conceito de vulnerabilidade social em territórios aos quais se destina a função protetiva da política de assistência social prevista na PNAS/2004. Trata-se de uma pesquisa teórica realizada por meio de revisão bibliográfica, complementada por pesquisa documental com base em fontes oficiais regulamentadoras da política de Assistência Social, publicadas pelo Ministério de Desenvolvimento Social e Combate à Fome, bem como, em documentos produzidos por órgãos de pesquisa que investigam a temática das vulnerabilidades sociais, definidas pela política de assistência social, sob a lógica territorial. Explica como a proteção social não contributiva, garantida pela Política de Assistência Social, se ocupa das vulnerabilidades e dos riscos que indivíduos ou famílias enfrentam na trajetória de seu ciclo de vida, em decorrência de imposições sociais, econômicas e políticas e de ofensas à dignidade humana. Demonstra que as vulnerabilidades sociais constituem um fenômeno multidimensional e complexo, definido por meio de indicadores socioeconômicos, demográficos, habitacionais, de saúde, educacionais, dentre outros. O estudo conclui que as vulnerabilidades podem ser agravadas em territórios onde inexistem equipamentos públicos de acesso a direitos socioassistenciais, ou seja, onde os indivíduos dependem apenas da capacidade protetiva do território vivido.
\end{abstract}

Palavras Chave: Vulnerabilidade social. Território vivido. Proteção social.

\begin{abstract}
:
This article aims to examine the concept of social vulnerability in territories to which the intended protective function of social assistance policy envisaged in PNAS/2004. This is a theoretical study by means of literature review, supplemented by documentary research in regulatory official sources of social assistance policy,
\end{abstract}

\footnotetext{
* Mestre em Serviço Social e Política Social - Universidade Estadual de Londrina. Docente do curso de Serviço Social da UNESPAR/FAFIPA - Universidade Estadual do Paraná - Campos de Paranavaí/PR. priscilasemzezem@hotmail.com

** Doutora em História e Sociedade pela UNESP, Assis/SP, Docente e pesquisadora do Departamento de Serviço Social da UEL. Coordenadora do Programa de Pós-graduação em Serviço Social e Política Social e do Núcleo de Estudos e Pesquisas sobre Gestão de Políticas Sociais da UEL. jolinda@uel.br
} 
published by the Ministry of Social Development and Hunger as well as the documents produced by research agencies that investigate the theme of social vulnerabilities defined by the social assistance policy on the territorial logic. Explains how noncontributory social protection guaranteed by the Social Assistance Policy deals with the vulnerabilities and risks that the individual or families face in the path of their life cycle, by a result of social impositions, and political and economic offenses to human dignity. Shows that social vulnerabilities pose in multidimensional and complex phenomenon defined by socioeconomic, demographic, housing, health, education within other indicators. Concludes that they may be aggravated in territories where there are no public services for access to social assistance rights, in other words, depend on the protective capacity of the lived territory.

Key Words: Social vulnerability. Lived territory. Social protection.

\section{Introdução}

A Política Nacional de Assistência Social, pautada nos ditames da Constituição de 1988, garante proteção social não contributiva, ou independente de contribuição, a famílias e indivíduos em situação de vulnerabilidade e risco social.

As vulnerabilidades sociais referenciadas pela política não se restringem às condições de pobreza, mas abarcam, igualmente, vitimizações, fragilidades e contingências que o cidadão, a cidadã e suas famílias enfrentam na trajetória de seu ciclo de vida, em decorrência de imposições sociais, econômicas e políticas.

Assim compreendidas, as vulnerabilidades sociais vinculam-se a situações de empobrecimento da classe trabalhadora, relacionadas a dificuldades materiais para a manutenção da sobrevivência, mas, também, a dificuldades relacionais e culturais, pois estas interferem na forma de viver dos trabalhadores e de suas famílias. Tais situações se manifestam de acordo com o ciclo vital das famílias dos usuários da política de assistência social, em diferentes territórios onde habitam. Como afirmam Couto, Yazbek e Raichelis (2010, p. 50), “o território é o terreno das políticas públicas, onde se concretizam as manifestações da questão social e se criam os tensionamentos e as possibilidades para seu enfrentamento. "Assim, a abordagem do território torna-se fundamental para a compreensão do conceito de vulnerabilidade social, posto que nele se determinam as condições de vida dos segmentos populacionais vulnerabilizados.

No documento da Política Nacional de Assistência Social - PNAS/2004, um dos desafios expressos é a necessidade de se criar indicadores de vulnerabilidade social territorial, para além do acesso à renda, que indiquem, também, a capacidade de dar 
respostas a diversas situações vivenciadas por sujeitos e famílias em condição de queda de bem-estar (BRASIL, 2005).

Este estudo tem por objetivo compreender o conceito de vulnerabilidade social e desvendar as várias dimensões que o compõe, a partir de uma análise do aspecto territorial, tendo como foco a função protetiva da política de assistência social. Utilizou-se como metodologia uma revisão bibliográfica, com base em autores que discutem essa temática na atualidade, e uma pesquisa documental, que teve como fonte documentos oficiais do Ministério de Desenvolvimento Social e Combate à Fome, bem como, os produzidos por órgãos de pesquisa que investigam a questão.

\section{Vulnerabilidade social}

Os estudos desenvolvidos sobre vulnerabilidade social demonstram que seu conceito é multifacetado devido às inúmeras situações que podem atingir indivíduos, famílias ou coletividades e, segundo Nery (2009), engloba várias dimensões, entre as quais: a dos bens materiais, a sócio-demográfica, a ambiental e a afetivo-relacional.

Há que se considerar que os primeiros estudos encontrados na literatura explicam as vulnerabilidades apenas a partir do viés econômico, pois se fundamentam em análises da capacidade de mobilidade social, partindo do pressuposto de que o fator econômico influencia na redução de oportunidades, o que interfere, diretamente, nas possibilidades de acesso a bens e serviços.

A partir da década de 1990, quando se esgota a matriz analítica pautada na concepção de pobreza reduzida aos aspectos econômicos e se introduz a discussão sobre riscos sociais, inseguranças e desproteção, aprofundam-se os estudos sobre as vulnerabilidades.

\footnotetext{
A temática estava mais voltada para o sentido de conhecer os setores mais desprovidos da sociedade (uma vez que se utilizava de indicadores de acesso ou de carências de satisfação das necessidades básicas) do que para compreender os determinantes do processo de empobrecimento. Com isso, foram delineados os grupos de risco na sociedade, com uma visão focalizada do indivíduo e não no contexto social que produziu a vulnerabilidade (MONTEIRO, 2011, p. 3).
}

Na América Latina, destacam-se os estudos de Moser (apud MONTEIRO, 2011), cuja pesquisa apontou que os riscos de mobilidade social descendente não se apresentavam 
apenas para a população pobre, mas para a sociedade em geral, uma vez que a desproteção e a insegurança transcendem a capacidade de satisfação das necessidades básicas.

Carneiro (2009) afirma que não é somente a população pobre que sofre com as inseguranças, mas a população em geral, além de destacar que a noção de proteção está relacionada a recursos específicos para o enfrentamento de situações de vulnerabilidade, chamados de "ativos":

[...] por ativos se consideram os diferentes tipos de recursos que as pessoas e famílias possuem e podem mobilizar como estratégias de resposta aos eventos de risco. O conjunto de ativos considerados varia de acordo com a perspectiva teórica adotada do enfoque da vulnerabilidade e não existe consenso sobre quais ativos devem ser reconhecidos como centrais. A tipologia de Caroline Moser, por exemplo, considera como ativos o trabalho, o capital humano, a moradia, as relações familiares, o capital social; outras abordagens consideram como ativos o capital natural, físico, humano, financeiro e social (CARNEIRO, 2009, p. 404).

O aprofundamento da compreensão dos "ativos" é possível quando se analisa o conceito de vulnerabilidade social apresentado nos documentos oficiais. Para o entendimento das dimensões conceituais expressas na Política de Assistência Social, foram consultados os “Cadernos de Orientações do PAIF" (BRASIL, 2012), os estudos do DIEESE Departamento Intersindical de Estatística e Estudos Socioeconômicos (2007, apud BRASIL, 2012) e estudos dos autores Kaztmam (1999 apud BRASIL, 2012) e Marandola Junior e Hogan (2006 apud BRASIL, 2012).

Para Kaztmam (1999 apud BRASIL, 2012), as vulnerabilidades resultam da relação entre duas variáveis: estrutura de oportunidades e capacidades dos lugares. A estrutura de oportunidades explica-se pela composição entre o mercado, a sociedade e o Estado. No âmbito do mercado, localizam-se a estrutura ocupacional e os empregos. A sociedade congrega o chamado "capital social", ou seja, as relações interpessoais de apoio mútuo, geradas com base em princípios de reciprocidade, que ocorrem, por exemplo, na organização familiar, na comunidade, nos grupos étnicos ou na religião. Por fim, a estrutura de oportunidades tem também o Estado como componente e compreende as políticas de bem-estar e as estruturas de representação de demandas e interesses, como, por exemplo: conselhos de direitos.

Em relação ao conceito de capacidades dos lugares, o autor destaca os territórios como espaços de sobrevivência, onde são consideradas as possibilidades de acesso e as 
condições habitacionais, sanitárias, de transporte, de serviços públicos, entre outros fatores que incidem, diretamente, no acesso diferencial à informação, às oportunidades e, consequentemente, aos direitos.

Kaztmam (1999 apud BRASIL, 2012) acrescenta, ainda, que a situação de vulnerabilidade dos atores sociais não depende somente de sua capacidade de gerenciamento de ativos, pois também sofre influência do contexto histórico, econômico e social, que é formado por oportunidades e precariedades. A superação da situação de vulnerabilidade depende, igualmente, da intermediação e da proteção oferecida pela estrutura estatal, pois só assim os atores sociais conseguirão usufruir dos diferentes tipos de ativos necessários para responder às situações de vulnerabilidade vigentes.

Estudos realizados pelo DIEESE (apud BRASIL, 2012) apontam que a vulnerabilidade define a zona intermediária instável, que conjuga a precariedade do trabalho, a fragilidade dos suportes de proximidade e a falta de proteção social. Neste contexto, se ocorrer algo, como, por exemplo, uma crise econômica, aumento do desemprego e/ou generalização do subemprego, a zona de vulnerabilidade dilata-se, avança sobre a zona de integração e gera a desfiliação. Nesse sentido:

\begin{abstract}
A vulnerabilidade de um indivíduo, família ou grupos sociais refere-se à maior ou menor capacidade de controlar as forças que afetam seu bem-estar, ou seja, a posse ou controle de ativos que constituem os recursos requeridos para o aproveitamento das oportunidades propiciadas pelo Estado, mercado ou sociedade: a) físicos - meios para o bem-estar - moradia, bens duráveis, poupança, crédito; b) humanos: trabalho, saúde, educação (capacidade física e qualificação para o trabalho); e c) sociais - redes de reciprocidade, confiança, contatos e acessos à informação (BRASIL, 2012, p. 12)
\end{abstract}

Para atestar a condição de vulnerabilidade social, os documentos oficiais postulam que se deve considerar a situação em que se encontram as pessoas/famílias a partir da análise dos seguintes elementos: inserção e estabilidade no mercado de trabalho, debilidade de suas relações sociais e, além disso, o grau de regularidade e de qualidade de acesso a serviços públicos ou outras formas de proteção social.

Para Marandola Junior e Hogan (apud BRASIL, 2012), vulnerabilidade é um novo termo utilizado para compor estudos sobre a pobreza, que se relaciona aos utilizados no passado, tais como: exclusão/inclusão, marginalidade, apartheid, periferização, segregação, dependência, entre outros. Os autores explicam que o termo tem sido 
empregado também designar restrição de bens de cidadania - seja em função de uma diminuição de renda ou de perda de capital social.

Cabe, aqui, uma análise sobre a concepção de vulnerabilidade social pela via dos "ativos" que fundamentam os documentos oficiais da política de assistência social, quanto à estrutura de oportunidades, de acordo com Kaztmam (apud BRASIL, 2012), que transfere a responsabilidade da situação de risco ou vulnerabilidade ao próprio indivíduo, que não consegue acessar o conjunto de recursos que the são disponibilizados. Entretanto, conforme Castilho (2012), a materialidade da proteção social revela limitações de ordem estrutural, na medida que não dispõe de condições objetivas no que se refere à oferta publica de serviços, que, no Brasil, se apresenta ineficiente.

Paulilo e Jeolás (2000) ressaltam que o conceito de vulnerabilidade social precisa ser pensado para além do plano individual, mas, igualmente, através do plano social e programático ou institucional:

O plano social inclui condições socioeconômicas, acesso à informação, escolarização, garantia de acesso aos serviços de saúde, garantia de respeito aos direitos humanos, situação sociopolítica e cultural da mulher. O plano programático ou institucional refere-se a serviços, programas, projetos e atividades voltadas para combater a epidemia de forma contínua e integrada (PAULILO; JEOLÁS, 2000, p. 41).

As autoras demonstram que estar vulnerável e exposto a riscos não depende da vontade singular, mas de fatores externos que podem contribuir para a situação: em primeiro lugar, os aspectos econômicos, sociais e culturais; em segundo, a oferta de serviços para determinadas demandas. Para que haja superação da condição de vulnerabilidade, é necessária uma articulação entre os dois fatores.

Dessa forma, a implementação de uma Política de Assistência Social deve considerar, como aspectos fundamentais em uma análise das vulnerabilidades, tanto o estudo dos determinantes sócio-territoriais das situações vivenciadas pelas populações às quais se destina, como da oferta e disponibilidade de um conjunto de recursos, bens, serviços, programas e benefícios que sejam capazes de prover a proteção social, como condição de vigilância, e a prevenção dessas situações de vulnerabilidade social.

\section{Vulnerabilidades dos usuários da política de assistência social}


A PNAS /2004 (BRASIL, 2005) explicita que os usuários da política de Assistência Social são os sujeitos da proteção social não contributiva, aos quais devem ser garantidas as seguintes seguranças: de sobrevivência (de rendimento e de autonomia); de acolhida; de convívio ou vivência familiar.

\begin{abstract}
Constitui o público usuário da Política de Assistência Social, cidadãos e grupos que se encontram em situações de vulnerabilidade e riscos, tais como: famílias e indivíduos com perda ou fragilidade de vínculos de afetividade, pertencimento e sociabilidade; ciclos de vida; identidades estigmatizadas em termos étnico, cultural e sexual; desvantagem pessoal resultante de deficiências; exclusão pela pobreza e, ou, no acesso às demais políticas públicas; uso de substâncias psicoativas; diferentes formas de violência advinda do núcleo familiar, grupos e indivíduos; inserção precária ou não inserção no mercado de trabalho formal e informal; estratégias e alternativas diferenciadas de sobrevivência que podem representar risco pessoal e social (BRASIL, 2005, p. 34).
\end{abstract}

Quando se analisa o conceito de vulnerabilidade social pela ótica da política de assistência social, percebe-se que a pobreza é reconhecida como uma das condições que a caracterizam, mas a concepção de pobreza não se reduz somente à insuficiência de renda, posto que esta é desencadeadora de outras dimensões das necessidades humanas, assim, é necessário investigá-la como um fenômeno multidimensional e complexo.

Yazbek (2007) explica que a pobreza, para além da ausência de renda, gera uma situação de subalternidade, relacionada ao plano subjetivo, pela ausência de poder de mando, de decisão, criação e direção. Desse modo, a subalternidade faz parte do mundo dos dominados, dos submetidos à exploração e à exclusão social, econômica, política e cultural, assim, constitui um processo de interiorização das condições objetivas vividas por estes sujeitos. Além disso, a situação de subalternidade está associada a um quadro de necessidades objetivas e subjetivas, desse modo, "não se reduz às privações materiais, alcançando diferentes planos e dimensões da vida do cidadão. " (COUTO; YAZBEK; RAICHELIS, 2010, p. 40).

Estudos têm demonstrado que existe um vasto contingente da população que não é considerado como pobre quando se analisa sua renda em termos financeiros, mas pode ser considerado vulnerável. "Nem todos os que se encontram em situação de vulnerabilidade são pobres - situados abaixo de alguma linha monetária da pobreza - nem todos os pobres são vulneráveis da mesma forma. " (CARNEIRO, 2009, p. 170). 
Para Sposati (2009), estar em situação de vulnerabilidade social não significa, necessariamente, estar na linha da pobreza. Esta agrava as situações de vulnerabilidade, os riscos e as fragilidades, mas não se pode apontar que vulnerabilidades, riscos e fragilidades existem por causa da pobreza.

Diante dessa compreensão, constituem usuários da política de assistência social não somente os que se encontram em situação de ausência de renda, mas, igualmente, os cidadãos que estão fora dos canais de proteção pública: trabalho, serviços sociais públicos e redes sociorrelacionais.

O documento "Caderno de Orientações do PAIF" (BRASIL, 2012) também afirma que vulnerabilidade não é sinônimo de pobreza. A pobreza é uma condição que agrava a vulnerabilidade vivenciada pelas famílias; também não é um estado, uma dada condição, mas uma zona instável que as famílias podem atravessar, nela recair ou nela permanecer ao longo de sua história; é um fenômeno complexo e multifacetado, que não se manifesta sempre da mesma forma, o que exige uma análise especializada para sua apreensão e para a formulação de respostas intersetoriais para seu enfrentamento; se ela não for compreendida e enfrentada, tende a gerar ciclos intergeracionais de reprodução de situações de vulnerabilidade vivenciadas; ou ainda, se não prevenida ou enfrentada tende a se tornar uma situação de risco. Essa forma de analisar a pobreza possibilita à assistência social uma visão menos determinista e mais complexa das situações de pauperismo, de modo a dar um sentido dinâmico para o estudo das desigualdades, a partir da identificação de zonas de vulnerabilidade, o que propicia um maior poder explicativo sobre uma realidade social composta por uma heterogeneidade de situações de desproteção social.

As manifestações de vulnerabilidade são caracterizadas tanto pela ausência de recursos, quanto pela ausência de defesas do indivíduo para enfrentar situações de incerteza no ciclo de vida. Estar em vulnerabilidade social significa ter as potencialidades de respostas alteradas ou diminuídas frente a situações de risco ou constrangimentos naturais da vida; indica uma predisposição à precarização, à vitimização e à agressão, mas, também, capacidade ou resiliência, ou seja, uma condição tal capaz de resistir e construir estratégias para conviver em ambientes desfavoráveis e circunstâncias difíceis, uma disposição para enfrentar confrontos e conflitos. 
Em relação à operacionalização da noção de vulnerabilidade, com base no público usuário da política de assistência social, consta, na Norma Operacional Básica do Sistema Único da Assistência Social:

O público é constituído por famílias que apresentam pelo menos uma das características listadas a seguir: domicílios com infraestrutura inadequada (critério IBGE); família com renda familiar per capita inferior a um quarto de salário mínimo; família com renda familiar per capita inferior a meio salário mínimo, com pessoas de 0 a 14 anos e responsável com menos de quatro anos de estudo; família em que uma chefe mulher, sem cônjuge, com filhos menores de 15 anos e analfabeta; família em que uma pessoa com 16 anos ou mais, desocupada (procurando trabalho) com quatro ou menos anos de estudo; família em que uma pessoa com 10 a 15 anos que trabalhe; família em que uma pessoa com 4 a 14 anos que não estude; família com renda familiar per capita inferior a meio salário mínimo, com pessoas de 60 anos ou mais; família com renda familiar per capita inferior a meio salário com uma pessoa com deficiência (BRASIL, 2005, p. 51-52).

Dessa forma, é evidente que as condições de pobreza e vulnerabilidade devem ser associadas a um quadro de necessidades objetivas e subjetivas, somadas a dificuldades materiais, relacionais e culturais, que interferem na reprodução social dos usuários da política de assistência social, o que torna fundamental situá-las no contexto do espaço territorial onde se localizam, pois é nele que ocorrem tanto as vulnerabilidades quanto os mecanismos para seu enfrentamento e proteção.

\section{Indicadores de vulnerabilidades sociais}

Por meio de indicadores sociais é possível interpretar as vulnerabilidades do público alvo da política de assistência social. Eles permitem estudar uma dada realidade através de números que podem subsidiar o processo de planejamento, gestão e avaliação de políticas públicas. Os indicadores sociais apresentam e representam, em números, dados que levam à compreensão das condições de vida de pessoas, famílias, grupos, cidades, regiões e países, em diferentes áreas, como: saúde, educação, demografia, renda e pobreza etc. (ORGANIZAÇÃO DAS NAÇÕES UNIDAS, 2005).

Para Koga (2011), além disso, os indicadores também representam significados de situações vividas no cotidiano da cidade, pois abarcam pessoas, serviços, poderes, instituições, organizações, economias. 
Embora já tenha havido uma evolução na construção de indicadores para analisar a pobreza para além da questão da renda, ou seja, como algo multidimensional, existem críticas em relação aos indicadores que a medem, pois, segundo Carneiro (2005), a elaboração de índices comparativos (Índice de Desenvolvimento Humano e Índice de Pobreza Humana) não permite a verificação da inter-relação entre as diferentes dimensões que os compõem, isto é, se educação, saúde e renda, por exemplo, de fato, se relacionam.

Para Koga (2011), os dois indicadores citados constituem "Medidas Genéricas Urbanas", caracterizadas por apresentar um alto grau de identificação de determinadas condições de vida e de setores da sociedade, especialmente, os mais vulneráveis. Suas principais características são a identificação de indicadores por segmentos relacionados à pobreza e à escala de gradação das condições de vida. Sua divisão se dá por meio de medidas sociais residuais caracterizadas como "Linha de Pobreza" e "Linha de Indigência" e, nesse sentido, a pobreza é entendida no âmbito da renda. Além desses indicadores de Medidas Genéricas Urbanas, a autora considera importante acrescentar os indicadores de "Medidas Sociais Temáticas" e de "Medidas Sociais Complexas".

Como Medidas Sociais Temáticas, destacam-se os cálculos de desigualdade de renda propostos pelo PNUD, como o Índice de Gini e o Índice de Theil. Para caracterizar as Medidas Sociais Complexas, a metodologia utilizada é a do Índice de Desenvolvimento Humano, que trabalha com a inter-relação dos indicadores: renda, educação e expectativa de vida.

O Índice de Gini é o indicador que mede o grau de concentração de renda em uma sociedade. Ele é apresentado em valores que variam de 0 a 1 . Quanto mais perto de 0 , significa que o país tem menor desigualdade, quanto mais próximo de 1 , maior é a desigualdade. Em 2004, o valor do Índice, no Brasil, era de 0,591, um dos maiores do mundo. Isto significa que os $10 \%$ mais ricos ficam com $50 \%$ do total da renda, e os $50 \%$ mais pobres ficam com apenas $10 \%$ da renda gerada no país (ORGANIZAÇÃO DAS NAÇÕES UNIDAS, 2005).

Segundo Koga (2011), o Índice de Gini considera a população com 10 anos de idade ou mais, com rendimento, deixando excluídos os que não possuem renda, o que o torna um índice excludente, pois, em seu cálculo, não é considerado o peso dos que, 
potencialmente, poderiam ter renda, mas não a têm. É um índice que se preocupa com a faixa de renda, não levando em consideração a localidade dos indivíduos.

Outro exemplo é o IDH (Índice de Desenvolvimento Humano), segundo o qual, o desenvolvimento humano está relacionado a capacidades. Ele é formado por indicadores que medem diferentes aspectos da realidade, entre os quais, três são básicos: longevidade, conhecimento e padrão de vida. Este índice é calculado com base em três variáveis e mede, assim, o nível de desenvolvimento do país, da região e dos municípios. (ORGANIZAÇÃO DAS NAÇÕES UNIDAS, 2005)

O IDH trouxe mudanças na forma de identificar a situação da população, pois rompeu com o tradicional índice comparativo entre países, o genérico e unilateral PIB per capita, entretanto, os dados levantados representam situações mais gerais do território em questão: país, estado e município, o que o torna um indicador para territórios administrativos. Eles identificam situações/condições de áreas geográficas, não são capazes, por exemplo, de estimar o grau de desenvolvimento ou carência de cada família, pois não levam em consideração as particularidades das famílias em determinada região (BARROS; CARVALHO; FRANCO, 2003).

Com o objetivo de aprofundar o conhecimento da realidade de regiões, Barros, Carvalho e Franco (2003) propõem a construção de um indicador sintético, no mesmo espírito do IDH, calculável em nível de cada família, que possa ser, facilmente, aplicável a qualquer grupo demográfico, tais como negros ou famílias chefiadas por mulheres, como é feito, tradicionalmente, com os indicadores de pobreza. Desta forma, foi construído um indicador específico, denominado de IDF$^{1}$, que deve levar em consideração diversas dimensões da pobreza para além da insuficiência de renda.

O IDF (Índice Desenvolvimento Familiar) considera seis dimensões, 26 componentes e 48 indicadores. São realizadas 48 perguntas às famílias, que devem responder sim ou não. Cada sim é computado como algo positivo e aumenta a pontuação da família em direção a um maior índice de desenvolvimento. O IDF pode variar de 0 (para famílias na pior situação possível) a 1 (para famílias na melhor situação possível).

As seis dimensões das condições de vida, avaliadas a partir das informações reunidas na PNAD e sintetizadas no IDF, são: a) ausência de vulnerabilidade; b) acesso ao

\footnotetext{
${ }^{1}$ Buscar maiores informações em: http://www.ipea.gov.br/pub/td/2003/td_0986.pdf
} 
conhecimento; c) acesso ao trabalho; d) disponibilidade de recursos; e) desenvolvimento infantil; e f) condições habitacionais (BARROS; CARVALHO; FRANCO, 2003).

Dessa forma, as dimensões básicas das condições de vida, com exceção das condições de saúde, puderam ser incluídas. Cada uma dessas seis dimensões representa, em parte, o acesso aos meios para as famílias satisfazerem suas necessidades e, em outra parte, a consecução de tais objetivos, isto é, a satisfação efetiva das necessidades. Essas dimensões se desdobraram em componentes que servirão para a elaboração dos indicadores.

Para melhor compreensão, os autores explicam cada uma das dimensões. Sobre a primeira (ausência de vulnerabilidade), explanam que a vulnerabilidade de uma família é medida pelo volume adicional de recursos que ela requer para satisfazer suas necessidades básicas, em relação ao que seria requerido por uma família-padrão. Utilizam-se, então, de cinco componentes para especificar a ausência de vulnerabilidade de uma família: fecundidade, atenção e cuidados com crianças adolescentes e jovens, atenção e cuidados especiais com idosos, razão de dependência econômica e presença da mãe.

A dimensão denominada acesso ao conhecimento abarca três componentes: o analfabetismo, a escolaridade formal e a qualificação profissional. Quanto ao componente acesso ao trabalho, devem ser consideradas: a disponibilidade de trabalho e a qualidade e a produtividade dos postos de trabalho disponíveis.

À medida que a grande maioria das necessidades básicas de uma família pode ser satisfeita graças a bens e serviços adquiridos no mercado, a renda familiar per capita passa a ser um recurso fundamental. Embora a origem dos recursos não seja relevante para a satisfação das necessidades de uma família, a sustentabilidade e o grau de independência da mesma dependem da parcela que é gerada autonomamente e da parcela que é recebida como transferências de outras famílias ou do governo.

Sobre a dimensão do desenvolvimento infantil, é possível captar quatro componentes: proteção contra o trabalho precoce; acesso à escola; progresso escolar e mortalidade infantil.

As condições habitacionais representam uma das principais dimensões das circunstâncias de vida de uma família, devido a sua íntima relação com as condições de saúde. Em virtude da informação disponível na PNAD, nesse quesito, podem ser avaliados 
diversos componentes, tais como: propriedade do imóvel, déficit habitacional, abrigabilidade, acesso adequado à água, acesso adequado a esgotamento sanitário, acesso à coleta de lixo, acesso à eletricidade e acesso a bens duráveis. No entanto, os autores analisam que não há informações sobre alguns componentes importantes das condições habitacionais, tais como: falta de segurança, separação das funções entre os cômodos disponíveis, natureza do entorno e distância da escola e do centro de saúde mais próximos (BARROS; CARVALHO; FRANCO, 2003).

Os autores explicam que as estimativas revelam que, enquanto $9 \%$ das famílias brasileiras apresentam um IDF inferior a 0,50, 33\% delas revelam IDF inferior a 0,67, o que demonstra que grande parte das famílias, segundo as estimativas do IDF, ainda se encontram nas piores condições possíveis.

Para Barros, Carvalho e Franco (2003), a inovação desse indicador é que, além de ser calculado para cada família, ele pode, não apenas obter o grau de desenvolvimento de bairros, municípios ou países, mas, também, de grupos demográficos, como negros, crianças, idosos ou analfabetos. Além disso, pode estimar o grau de desenvolvimento da própria família e reconhecer que, mesmo em bairros pobres, existem famílias não-pobres, ao passo que, mesmo em bairros de poder aquisitivo mais alto, uma significativa parcela das famílias ainda permanece em níveis de desenvolvimento muito baixos.

Com base na regulação nacional, Filgueiras (2004) explica que a operacionalização da vulnerabilidade, na Política de Assistência Social, permite analisar as famílias que apresentam características de alta vulnerabilidade, conforme as variáveis de natureza censitária e os territórios onde estas estão concentradas.

A taxa de vulnerabilidade social, definida na NOB/Suas, é um importante indicador da necessidade de oferta de serviços de Proteção Básica. Cada município deve identificar o(s) território(s) de vulnerabilidade social e nele(s) implantar um CRAS, de forma a aproximar os serviços dos usuários (BRASIL, 2005, p. 5).

Entretanto, Magalhães (2009) aponta que as variáveis que compõem os territórios apresentam uma característica censitária, pois os perfis não incluem os aspectos relacionais, como "laços familiares e comunitários", que são o objeto da ação da Proteção Social Básica. 
A vulnerabilidade, como já foi apontado, é uma noção multidimensional, pois afeta indivíduos, grupos e comunidades em planos distintos de bem-estar, de diferentes formas e intensidade. Neste sentido, conforme Busso, citado no IPVS (FUNDAÇÃO SISTEMA ESTADUAL DE ANÁLISE DE DADOS, 2011):

\footnotetext{
Entre os fatores que compõem as situações de vulnerabilidade social estão: “a fragilidade ou desproteção ante as mudanças originadas em seu entorno, o desamparo institucional dos cidadãos pelo Estado; a debilidade interna de indivíduos ou famílias para realizar as mudanças necessárias a fim de aproveitar o conjunto de oportunidades que se apresenta; a insegurança permanente que paralisa, incapacita e desmotiva no sentido de pensar estratégias e realizar ações com o objetivo de lograr melhores condições de vida.
}

Além de considerar a privação de renda como fator central, as análises sobre situação de vulnerabilidade devem incluir: a composição familiar, as condições de saúde, o acesso a serviços médicos e a sistema educacional de qualidade, a possibilidade de obtenção de trabalho com qualidade e remuneração adequadas, a existência de garantias legais e políticas etc.

A partir dessa concepção de vulnerabilidade social, podem ser apresentados, como exemplo, os estudos da Fundação Sistema Estadual de Análise de Dados (SEADE), do Estado de São Paulo, que serviram de base para a construção do IPVS (Índice Paulista de Vulnerabilidade Social), elaborado a partir de duas dimensões: a socioeconômica, composta pela renda apropriada pelas famílias e pelo poder de geração da mesma por seus membros, e a demográfica, relacionada ao ciclo de vida familiar. 
Quadro 1 - Classificação dos setores censitários segundo grupos de vulnerabilidade do IPVS

\begin{tabular}{|c|c|}
\hline Grupos & Características \\
\hline $\begin{array}{l}\text { Grupo } 01 \\
\text { Nenhuma } \\
\text { vulnerabilidade }\end{array}$ & $\begin{array}{l}\text { Engloba os setores censitários em melhor situação socioeconômica } \\
\text { (muito alta) com os responsáveis pelo domicílio possuindo os mais } \\
\text { elevados níveis de renda e escolaridade. Apesar de o estágio das } \\
\text { famílias no ciclo de vida não ser um definidor do grupo, seus } \\
\text { responsáveis tendem a ser mais velhos, com menor presença de } \\
\text { crianças pequenas e de moradores nos domicílios, quando } \\
\text { comparados com o conjunto do Estado de São Paulo. }\end{array}$ \\
\hline Grupo 02 & \\
\hline $\begin{array}{l}\text { Vulnerabilidade } \\
\text { muito baixa }\end{array}$ & $\begin{array}{l}\text { Abrange os setores censitários que se classificam em segundo lugar, } \\
\text { no Estado, em termos da dimensão socioeconômica (média ou alta). } \\
\text { Nessas áreas concentram-se, em média, as famílias mais velhas. }\end{array}$ \\
\hline Grupo 03 & \\
\hline $\begin{array}{l}\text { Vulnerabilidade } \\
\text { baixa }\end{array}$ & $\begin{array}{l}\text { Formado pelos setores censitários que se classificam nos níveis altos } \\
\text { ou médios da dimensão socioeconômica e seu perfil demográfico } \\
\text { caracteriza-se pela predominância de famílias jovens e adultas. }\end{array}$ \\
\hline $\begin{array}{l}\text { Grupo } 04 \\
\text { Vulnerabilidade } \\
\text { Média }\end{array}$ & $\begin{array}{l}\text { Composto pelos setores que apresentam níveis médios na dimensão } \\
\text { socioeconômica, estando em quarto lugar na escala em termos de } \\
\text { renda e escolaridade do responsável pelo domicílio. Nesses setores } \\
\text { concentram-se famílias jovens, isto é, com forte presença de chefes } \\
\text { jovens (com menos de } 30 \text { anos) e de crianças pequenas. }\end{array}$ \\
\hline $\begin{array}{l}\text { Grupo } 05 \\
\text { Vulnerabilidade } \\
\text { Alta }\end{array}$ & $\begin{array}{l}\text { Engloba os setores censitários que possuem as piores condições na } \\
\text { dimensão socioeconômica (baixa), estando entre os dois grupos em } \\
\text { que os chefes de domicílios apresentam, em média, os níveis mais } \\
\text { baixos de renda e escolaridade. Concentra famílias mais velhas, com } \\
\text { menor presença de crianças pequenas. }\end{array}$ \\
\hline $\begin{array}{l}\text { Grupo } 06 \\
\text { Vulnerabilidade } \\
\text { Muito Alta }\end{array}$ & $\begin{array}{l}\text { O segundo dos dois piores grupos em termos da dimensão } \\
\text { socioeconômica (baixa), com grande concentração de famílias } \\
\text { jovens. A combinação entre chefes jovens, com baixos níveis de } \\
\text { renda e de escolaridade e presença significativa de crianças } \\
\text { pequenas permite inferir ser este o grupo de maior vulnerabilidade } \\
\text { à pobreza. }\end{array}$ \\
\hline
\end{tabular}

Fonte: Silva (2012). 
Assim, a vulnerabilidade social, compreendida pelo IPVS, "decorre de fenômenos diversos, com causas e consequências distintas, obtém-se uma visão mais abrangente das condições de vida e dos riscos sociais que atingem os vários segmentos populacionais, bem como das possibilidades de sua superação ou minimização. " (FUNDAÇÃO SISTEMA ESTADUAL DE ANÁLISE DE DADOS, 2011).

Ressalta-se que esse indicador permite ao gestor público e à sociedade uma visão mais detalhada das condições de vida em seu município, com a identificação e a localização espacial das áreas que abrigam os segmentos populacionais mais vulneráveis à pobreza (FUNDAÇÃO SISTEMA ESTADUAL DE ANÁLISE DE DADOS, 2011).

Dessa forma, a criação de indicadores territorializados, expressos na PNAS (BRASIL, 2005), pode subsidiar o planejamento de ações que desencadeiam impactos na população atendida, proporcionando a redução de vulnerabilidades em determinado território.

Cabe considerar que foi criada, recentemente, pelo MDS, uma nova ferramenta, o IDV², Identificação de Localidades e Famílias em Situação de Vulnerabilidade, que é um aplicativo desenvolvido para a construção de mapas de pobreza, em nível de estados, municípios e setores censitários, que possibilita o levantamento de dados e indicadores de pobreza e vulnerabilidade em grupos populacionais específicos. Esse aplicativo foi criado para auxiliar gestores e agentes públicos a identificar áreas com maior concentração de famílias em situação de pobreza e/ou vulnerabilidade. Os dados e indicadores apresentados pelo IDV foram obtidos do Censo Demográfico 2010 e do Cadastro Único de Programas Sociais, de agosto de 2011. Os indicadores criados foram gerados a partir de levantamento de dados socioeconômicos.

Embora tenham sido criadas ferramentas de identificação das características dos territórios, observa-se que são utilizados indicadores sociais a partir de levantamentos socioeconômicos. Neste contexto, cabe considerar os apontamentos de Koga (2009), segundo o qual, o reconhecimento das vulnerabilidades sociais, em um determinado território, exige dos municípios investimentos na produção de informações mais desagregadas sobre a realidade socioeconômica, política e cultural. A autora ressalta que essa prática não tem sido usual nas prefeituras brasileiras, e sua ausência tem afetado não

\footnotetext{
2 Para maiores informações consultar Brasil (2012).
} 
só as políticas sociais como um todo, mas os que sofrem com a inexistência de serviços em determinado território, ou seja, a própria população.

Koga (2011) aponta, ainda, que, para a compreensão dos significados da relação entre território e políticas públicas, devem ser realizados estudos a partir das Medidas Intraurbanas, que se caracterizam pela busca de uma leitura mais aprofundada das desigualdades internas dos territórios analisados, no caso, os municípios brasileiros, sobre as seguintes questões: incidência das desigualdades sociais nos territórios; incidência da pobreza ou da vulnerabilidade; e escala de gradação das condições de vida.

Em seu estudo, a autora afirma que ser capaz de captar desigualdades existentes nos territórios das cidades representa um novo modo de olhar. Nesse sentido, a divisão territorial vai além do aspecto técnico-administrativo, sendo também um fator político. $\mathrm{Na}$ pesquisa, ela aponta e analisa seis metodologias que se complementam: Mapa da Exclusão/ Inclusão Social da cidade de São Paulo; Mapa da Pobreza de Curitiba; Mapa da Exclusão Social de Belo Horizonte; Índice de Qualidade de Vida Urbana de Belo Horizonte; Desenvolvimento Humano Sustentável no Recife Metropolitano e IDH do Rio de Janeiro. Os estudos intraurbanos realizados mostram que cada uma das cidades apresentou desigualdades, presença de exclusão social e pobreza interna, mas quando se efetua uma leitura geral das mesmas, estas demonstram altos níveis de condições de vida (KOGA, 2011).

Cabe ressaltar que, nessa perspectiva, não é descartada a compreensão da realidade com base nas medidas sociais genéricas (Índice de Gini, IDH), entretanto, as Medidas Intraurbanas propiciam o conhecimento do chão das cidades e evidenciam que o território faz parte do cotidiano da vida da cidade. Sua inserção como elemento de análise permite uma proximidade maior com a concretude das condições de vida das pessoas e dos lugares. Assim, essas medidas possibilitam reconhecer que a cidade e seus diferentes espaços possuem particularidades que potencializam a proposição de políticas públicas mais efetivas.

\section{As vulnerabilidades sociais e a proteção no território}

Compreender as vulnerabilidades sociais significa entender a mediação entre o acesso a direitos, rede de serviços e políticas públicas e a capacidade de sujeitos e grupos 
sociais de acessar esse conjunto de bens e serviços, de modo a exercer sua cidadania. Conforme Rizzotti (2009), a vulnerabilidade social está associada à insuficiência de uma rede de proteção que garanta às famílias o acesso aos direitos.

Nesse sentido, para a compreensão da vulnerabilidade social existente em determinado território, é necessário que se avalie a capacidade de alcance das políticas sociais e que se identifique os desafios e as tensões nelas embutidos, para que estas possam se efetivar na perspectiva proativa, preventiva e protetiva. Por outro lado, 0 enfrentamento também depende do reconhecimento e da efetivação de políticas sociais com vistas à ampliação de sua capacidade protetiva em um determinado território.

Assim, a compreensão das vulnerabilidades sociais, necessariamente, deve estar relacionada ao território como espaço de concretização das políticas públicas, ou seja, só partir do que o território tem para ofertar é possível diagnosticar, com a clareza, as circunstâncias que podem levar indivíduos e famílias a situações de vulnerabilidade social e risco social. Com base nesse levantamento, é possível articular recursos para a sua prevenção.

Conforme afirmam Lucena et al. (2010), é através da apreensão da dimensão territorial que se pode visualizar as complexas relações de dependência, distribuição e concentração de bens e os quadros de vulnerabilidade a que estão expostas as diferentes parcelas da população, já que o território é a expressão concreta de tais fenômenos.

Além disso, de acordo com Koga (2011), o território se constrói a partir dele próprio e das pessoas que o utilizam, desse modo, envolve tanto os aspectos objetivos como os subjetivos, que emergem através da manifestação de sofrimentos, desejos e expectativas. A pesquisadora afirma que pensar as políticas públicas a partir do território é empregar uma perspectiva redistributiva, pois, se as políticas públicas forem restritas ao estabelecimento prévio de públicos-alvo ou de demandas genéricas, apresentarão limitações, por considerarem as desigualdades concretas existentes nos diversos territórios.

A PNAS/2004, para prover a proteção social, reconhece a abordagem territorial como um elemento fundamental (BRASIL, 2005). Sposati (2009) explica que, para a concretude dessa política, há forte influência da territorialidade, pois esta só se instala e opera a partir 
de forças vivas e de ações com sujeitos reais. Este tipo de política se realiza a partir de um conjunto de relações e forças em movimento.

Diante disso, a organização dos serviços da Política de Assistência Social, na perspectiva da territorialidade, prevê a possibilidade de superação da fragmentação de ações e serviços e a proximidade da população, como afirmam Couto, Yazbek e Raichelis (2010, p. 53): “A territorialização é um elemento-chave para que os serviços sejam ofertados próximos à população, para que o território seja provido de recursos que melhorem as condições de vida da população. "

Nessa perspectiva, o território é entendido como um espaço permeado de relações, carências e necessidades, em que existem mecanismos de resistência e lutas coletivas:

\footnotetext{
O chão e suas circunstâncias deixam de ser um dado natural e tornam-se uma construção humana. Neste sentido afirmo que, sobre a topografia da natureza ergue-se uma topografia social, ela incorpora a concretude de condições e acessos como dois elementos imbrincados mutuamente e dependentes. Já não se está simplesmente falando de um lugar como vazio, mas do resultado da ocupação e da ação dos sujeitos cidadãos, ou quase cidadãos (KOGA, 2011, p. 16).
}

Para Koga (2007) a vulnerabilidade social de que trata a política de assistência social está relacionada às situações sociais presentes no lugar onde as pessoas vivem e aos equipamentos que o indivíduo e a família podem acessar em sua comunidade, sejam eles serviços, programas, projetos e ações existentes, no território, com o objetivo ofertar proteção.

Cabe ressaltar que as vulnerabilidades sociais precisam e devem ser prevenidas, reduzidas e corrigidas, pois levam a riscos sociais. As políticas públicas têm um papel fundamental nesse processo, pois sua capacidade protetiva se concretiza em ações de prevenção de situações de risco.

Segundo Sposati (2009), os riscos de que trata a Política de Assistência Social são os que provocam padecimentos, perdas, privações, danos e ofensas à integridade e à dignidade pessoal e familiar. Os modos como essas situações se manifestam encontram-se no cotidiano das pessoas, nos territórios onde vivem, e estes podem, em maior ou menor escala, expô-las a riscos. São considerados fatores de risco: a convivência familiar, comunitária e social; fenômenos de isolamento, desagregação, desfiliação, discriminação, 
apartação e exclusão; contingências da natureza; aspectos como etnia, gênero, religião e orientação sexual; desigualdade econômica etc.

Embora riscos e contingências sociais possam afetar todos os cidadãos, o que muda, para alguns, são os recursos de que dispõem para enfrentar tal situação, em decorrência de sua condição de vida e da cidadania precária. Assim sendo, as respostas a situações de risco podem ser mais ampliadas para uns do que para outros, ou seja, dependem dos mecanismos de proteção social de que os cidadãos dispõem em seu território, tais como: serviços, ações, programas e projetos (SPOSATI, 2009).

Apontamentos realizados por Silva (2012) são importantes para a compreensão de que o surgimento de vulnerabilidades e riscos não está relacionado, somente, a características de um território:

\begin{abstract}
Apesar, de algumas vulnerabilidades sociais estarem ligadas diretamente ao território, não se pode esquecer que "grande parte das vulnerabilidades sociais dos usuários da política de assistência social, não tem origem na dinâmica local, mas em processos estruturais". Não "enxergar" a totalidade é negar que os rumos da política econômica e de sua desvinculação da política social, a precarização e da insegurança do trabalho, o enfraquecimento das instituições de proteção social, o retraimento do Estado e das políticas sociais, a incerteza e insuficiência do orçamento para proteção social, da baixa cobertura dos programas, serviços e benefícios, afetam diretamente todos os cidadãos do país, principalmente aqueles que mais demandam por proteção social (SILVA, 2012, p. 99).
\end{abstract}

A vulnerabilidade e o risco devem ser compreendidos a partir de um conjunto de fatores de ordem estrutural, produzidos por políticas econômicas se contrapõem às políticas sociais. Esta relação desigual permite a destituição de direitos, a precarização das relações de trabalho e, entre outras consequências, a desconstrução dos mecanismos de proteção. "Não basta que as políticas públicas sejam descentralizadas pelos territórios da cidade, mais do que isso é preciso que estes territórios exerçam um papel de sujeito e não apenas de objeto das políticas públicas. " (KOGA, 2011, p. 296).

A leitura do território precisa levar em consideração que este espaço é permeado de significados, pois embute relações de vivência, encontrando-se, assim, em constante transformação. Desse modo, há que se estabelecer uma forma para se efetivar seu constante monitoramento, por meio do reconhecimento e da criação de mecanismos de proteção para afiançar seguranças sociais à população, potencializando-a para que possa prevenir e intervir em situações de vulnerabilidade social. 


\section{Considerações finais}

A política de assistência social, no Brasil, é recente e, a partir da instituição do Sistema Único de Assistência Social - SUAS, foram elaboradas as regulações necessárias para sua implementação e configuração como sistema protetivo de característica não contributiva. A cada regulamentação editada pelo Ministério de Desenvolvimento Social e Combate à Fome, surgem vários questionamentos, que, por sua vez, indicam a necessidade de novas adequações ou mesmo adaptações dessas normativas, no âmbito de um processo em construção.

Restam ainda grandes desafios que carecem de investigação e aprofundamento no que se refere à materialização dessa política na sociedade brasileira, que é tão complexa quando se leva em conta seus 5.564 municípios, localizados em territórios tão diversos.

A política de assistência social, ao se ocupar das vulnerabilidades e dos riscos que os indivíduos ou famílias enfrentam na trajetória de seu ciclo de vida, em decorrência de imposições sociais, econômicas e políticas e de ofensas à dignidade humana, entende que a proteção garantida pela assistência social não deve se restringir apenas à mitigação das condições de pobreza, mas também afiançar seguranças sociais.

Assim, sua função protetiva tem como objetivo a preservação da vida, para que não ocorra destruição e os indivíduos não entrem em situação de vulnerabilidade. Desse modo, as ações devem ser executadas antes, para que possam prevenir e prover seguranças sociais, por meio de serviços e benefícios que visem à prevenção, ao enfrentamento de situações de vulnerabilidade e risco e à proteção social

Nesse sentido, para compreender de que forma devem ser enfrentados a vulnerabilidade social e o risco, torna-se necessário conhecer o território, pois é nele que se desenvolvem as carências, as potencialidades e os mecanismos de proteção social.

Ao referenciar a vulnerabilidade social no campo da política de assistência social, é importante ressaltar sua intrínseca relação com a função protetiva desta política, ou seja, a capacidade de respostas qualificadas às necessidades dos que se encontram desprotegidos. 
A diminuição dos níveis de vulnerabilidade social deve se dar a partir do fortalecimento dos sujeitos pela disponibilização do acesso a bens e serviços, o que amplia suas condições de mobilidade social.

A mensuração da situação de vulnerabilidade social não parte somente das necessidades explicitadas pelos indivíduos ou famílias, mas também diz respeito aos recursos que esses sujeitos podem acessar no território vivido, tais como: serviços, programas, projetos e ações protetivas. Assim, a vulnerabilidade também está associada à insuficiência de uma rede de proteção que garanta às famílias o acesso aos direitos.

Embora os indicadores disponíveis sejam fundamentais para se compreender a vulnerabilidade social, a análise da realidade não deve ser restrita a estes, pois não levam em consideração as características particulares de cada território, com suas especificidades e mecanismos de acesso à proteção. Por isso, para a implementação de políticas, programas, projetos e ações, em um determinado território, é preciso identificar suas características e as relações sociais, os serviços, as demandas e as potencialidades ali existentes, pois, a partir dessa análise, podem ser criados canais de proteção para atender a população em suas necessidades.

Cabe ressaltar que construir um marco conceitual que relacione a vulnerabilidade social à política de assistência social ainda é um grande desafio, pois se trata de uma política recém criada no Brasil. Compreender a vulnerabilidade social expressa na PNAS/2004, portanto, não se restringe a um exercício intelectual. É necessário compreender os desafios e as tensões que se colocam para a efetividade dessa política em uma perspectiva proativa, preventiva e protetiva. $O$ enfrentamento das condições de vulnerabilidade social também depende do reconhecimento, da efetivação e da articulação das políticas sociais com vistas à ampliação de sua capacidade protetiva em um determinado território.

\section{Referências}

BARROS, R. P.; CARVALHO, M.; FRANCO, S. O índice de desenvolvimento da família (IDF). Texto para Discussão, Rio de Janeiro, n. 986, 2003. Disponível em:

<http://www.ipea.gov.br/pub/td/2003/td_0986.pdf>. Acesso em: 20 maio 2012.

BRASIL. Ministério de Desenvolvimento Social e Combate à Fome. Orientações técnicas sobre o PAIF: serviço de proteção e atendimento integral à família - PAIF, segundo a 
tipificação nacional de serviços socioassistenciais. Brasília: Ministério de Desenvolvimento Social e Combate à Fome, 2012.

Plano Brasil sem Misérias. Dados e estatísticas. Disponível em:

<http://www.brasilsemmiseria.gov.br/dados-e-estatisticas $>$. Acesso em: Acesso em: 20 maio 2012.

.Política nacional de assistência social PNAS/2004: norma operacional básica NOB/SUAS. Brasília: Ministério do Desenvolvimento e Combate à Fome, 2005.

CARNEIRO, Carla Bronzo Ladeira. Programas de proteção e superação da pobreza: concepções e estratégias de intervenção. 2005. Tese (Doutorado em Ciências Humanas: Sociologia e Política) - Universidade Federal de Minas Gerais, Belo Horizonte, 2005.

Vulnerabilidade, empoderamento e metodologias centradas na família: conexões e uma experiência para reflexão. In: BRASIL. Ministério do Desenvolvimento Social e Combate à Fome. Concepção e gestão da proteção social não contributiva no Brasil. Brasília: Ministério do Desenvolvimento Social e Combate à Fome, 2009. p. 171-203.

CASTILHO, C. F. V. A operacionalização do trabalho social com famílias nos CRAS de Maringá. 2012. Dissertação (Mestrado em Serviço Social e Política Social) - Universidade Estadual de Londrina, Londrina, 2012.

COUTO, B. R.; YAZBEK, M. C.; RAICHELIS, R. A política nacional de assistência social e o SUAS: apresentando e problematizando fundamentos e conceitos. In: COUTO, Berenice Rojas et al. (Org.). O sistema único de assistência social no Brasil: uma realidade em movimento. São Paulo: Cortez, 2010. p. 32-65.

FILGUEIRAS, C. A. C. Exclusão, risco e vulnerabilidade: desafios para a política social. In: CARNEIRO, Carla Bronzo Ladeira; COSTA, Bruno Lazzarrotti Diniz. Gestão social: o que há de novo? Belo Horizonte: Fundação João Pinheiro, 2004. p. 25-34.

FUNDAÇÃO SISTEMA ESTADUAL DE ANÁLISE DE DADOS. Índice paulista de vulnerabilidade social. 2011. Disponível em: <http://www.seade.gov.br/projetos/ipvs/>. Acesso em: 20 maio 2012.

KOGA, D. Medidas de cidades: entre territórios de vida e territórios vividos. São Paulo: Cortez, 2007.

. Medidas de cidades: entre territórios de vida e territórios vividos. São Paulo: Cortez, 2011.

- Vulnerabilidades e proteção social básica na agenda do CRAS. In: São Paulo. Secretaria de Assistência e Desenvolvimento Social. CRAS: marcos legais. São Paulo: Secretaria Estadual de Assistência e Desenvolvimento Social, 2009. p. 29-40. 
LUCENA. Bruna Barbosa de (et al). VULNERABILIDADE E TERRITÓRIO EM SÃO SEBASTIÃO DF. Anais XVI Encontro Nacional de Geógrafos. Porto Alegre/ RS. Realizado de 25 a 31 de julho de 2010.

MAGALHÃES, E. P. Combatendo a pobreza e enfrentando as vulnerabilidades: desafios para a articulação entre o Programa Bolsa Família e a Proteção Social Básica. In: BRASIL. Ministério do Desenvolvimento Social e Combate à Fome. Concepção e gestão da proteção social não contributiva no Brasil. Brasília: Ministério do Desenvolvimento Social e Combate à Fome, 2009. p. 401- 414.

MONTEIRO, S. R. R. O marco conceitual da vulnerabilidade social. In: SEMINÁRIO DE POLÍTICAS SOCIAIS DO MERCOSUL, 3., 2011, Pelotas. Anais... Pelotas, SEPOME, 2011.

NERY, Vania Baptista. O trabalho de Assistentes Sociais e Psicólogos na Política de Assistência Social- Saberes e Direitos em questão. Tese de Doutorado em pós- graduação em Serviço Social da Pontifícia Universidade Católica de São Paulo. São Paulo, 2009.

ORGANIZAÇÃO DAS NAÇÕES UNIDAS. Programa das Nações Unidas para o Desenvolvimento. Indicadores de pobreza e desenvolvimento humano: uma introdução. Belo Horizonte: PNUD, 2005.

PAULILO, M. A. S.; JEOLÁS, L. S. Jovens, drogas, risco e vulnerabilidade: aproximações teóricas. Serviço Social em Revista, Londrina, v. 3, n. 1, jul./dez. 2000.

RIZOTTI, M. L. A. Centro de referência especializado de assistência social (CREAS): a proposição de garantir atenção à situação de risco vulnerabilidade. In: MENDES, Jussara Maria Rosa; PRATES, Jane Cruz; AGUINSKY, Beatriz Gershenson. O sistema único de assistência social: as contribuições à fundamentação e os desafios de implantação. Porto Alegre: EDIPUCRS, 2009. p. 1-269.

SILVA, T. G. M. A vigilância social na política de assistência social: análise dos aspectos conceituais e operacionais no âmbito municipal. 2012. Dissertação (Mestrado em Serviço Social e Política Social) - Universidade Estadual de Londrina, Londrina, 2012.

SPOSATI, A. Modelo brasileiro de proteção social não contributiva: concepções fundantes. In: BRASIL. Ministério do Desenvolvimento Social e Combate à Fome. Concepção e gestão da proteção social não contributiva no Brasil. Brasília: Ministério do Desenvolvimento Social e Combate à Fome, 2009. p. 13-56.

YAZBEK, M. C. Classes subalternas e assistência social. 6. ed. São Paulo: Cortez, 2007 